\title{
PLATFORM LEADERSHIP AND STRATEGY OF SMALL AND MEDIUM ENTERPRISES ON DIGITAL TRANSFORMATION
}

\author{
Sun-A Min \\ Ph.D. Candidate, Seoul Business School, Seoul School of Integrated Sciences and \\ Technologies (aSSIST), Seoul, Korea \\ Bo-Young Kim \\ Associate Professor, Seoul Business School, Seoul School of Integrated Sciences and \\ Technologies (aSSIST), Seoul, Korea
}

\begin{abstract}
New sustainable growth approaches are expected from small and medium-sized enterprises (SMES) by the recent Fourth Industrial Revolution due to rapid technological development and the social and environmental changes caused by the COVID-19 pandemic. As IoT, AI, and big data technology rapidly develop, digital transformation has turned into firms' essential capability. The platform strategy to use a firm's external capability has become vital to SMEs seeking digitalization and sustainability. In such a context, this study identified the factors affecting SMEs' platform leadership and the strategies necessary for digital business consolidation and business continuity. It likewise employed a questionnaire survey targeting 376 Korean SMEs. According to the analytical results, SMEs' platform leadership had an advantageous effect on platform strategy which, in turn, positively influenced digital business consolidation and business continuity. However, platform leadership was identified as a factor not directly affecting digital business consolidation and continuity. This shows that platform leadership should be implemented alongside the platform strategy.
\end{abstract}

Key words: Platform Leadership, Platform Strategy, SMEs, Digital Transformation

Cite this Article: Sun-A Min and Bo-Young Kim, Platform Leadership and Strategy of Small and Medium Enterprises on Digital Transformation, International Journal of Management, 11(12), 2020, pp 2176-2188.

http://iaeme.com/Home/issue/IJM?Volume=11\&Issue=12 


\section{INTRODUCTION}

As digital technology rapidly develops, enormous changes occur throughout the economy and society, as well as to individuals. All companies, irrespective of the domain in the industrial field, are affected by digital platforms and networks. As mentioned in the report "Future of Jobs" at the Davos Forum, the Fourth Industrial Revolution through which companies can innovate their conventional management style is both an opportunity and a threat. The COVID-19 pandemic is globally accelerating the shift of the business ecosystem, centering on technology-based digital transformation. Therefore, digital transformation is becoming a concern of all organizations, regardless of region, country, business type, and size.

According to GE's 2017 business report, the sales of GE Digital was USD 4 billion based on December 2017, up 29\% compared to USD 3.1 billion based on the December 2015 report (GE Annual Report, 2017). A clothes shopping mall, "Style Nada," acquired by LOREAL at KRW 400 billion, raised the order picking's accuracy to $99 \%$ using a voice recognition-based release handling system. Likewise, finding an opportunity to secure productivity and added value through digital transformation in companies' fields are needed. However, SMEs' digitalization is notably delayed until now, compared to large corporations' adjustment. The reason is that digital transformation (DT or DX) does not merely mean the digitalization of simple products or services; competitiveness should be enhanced through new solution creation, operation innovation, and business foundation reestablishment using ICT. Activities pursuing new growth should also be carried out in almost all fields, including operation management processes, organizational culture, and business models (Chang et al., 2016; Cho et al., 2015).

What SMEs should most preferentially fortify to respond to digital transformation is securing platform competitiveness (Chesbrough \& Adrienne, 2006). SMEs should secure platform-based dynamic capabilities, obtain new business opportunities, and draw the firm's internal and external resources' flexible stratification. For corporate innovation, there is a need to seek a digital network mode platform strategy as current society enters a hyperconnected setting, involving O2O, omnichannel, and sharing economy (Hirano \& Hagiu, 2011). If a win-win network between corporate ecosystems is formed based on platform, a win-win strategy by which a company finds answers can be enhanced. Further, customers may transform into partners, firms need not independently strive to manufacture, and business market values can be enhanced. SMEs need to be equipped, therefore, with platform leadership and strategy to promote digital-based innovation.

Many previous studies related to the platform business conducted research on platform provider-centered strategy (Torkkeli \& Tuominen, 2002; Van Alstyne et al., 2002; Yoon \& Seo, 2016). However, this study defined platform from the organizational perspective and discussed the platform leadership and strategy that the companies, the platform producers, need. It examined the relationship between SMEs' business digitalization and platform strategy to improve future competitiveness through business digitalization. It empirically presented the effects of SMEs' platform leadership and strategy on firms' business continuity, not to mention on digital business consolidation. Currently, the environmental shift of the business ecosystem is beyond simple technology change. Business model recreation and diversification should flexibly cope with market variability, and so firms cannot concentrate on just internal resources and capabilities. SMEs need to accurately understand the platform's essence, secure platform leadership through cooperation with content providers, and create network effects. The improvement of platform leadership and strategy will eventually accelerate business digitalization, and it will become a factor to lead the business in the new management environment continuously. This study emphasized the importance of SMEs' platform leadership and strategy and discussed the implementation direction from this aspect. 


\section{HYPOTHESES DEVELOPMENT}

\subsection{Platform Leadership and Strategy}

A platform is defined as "a tangible/intangible structure designed with a common purpose to be used for diverse functions starting from the place where people get on and get off the train at station" in lexical meaning. In the business world, mainly, a platform acts as a catalyst to make value exchange actively occur and create a new market value (Evans and Schmalesee, 2008). The platform's roles can be examined by dividing its area into consumers' perspectives and entrepreneurs' perspectives. The consumers' perspective is classified into communication, entertainment, e-commerce, comparison, and information offering, centered on consumers' activities.

The platform is divided into a software platform, e-commerce platform, payment and financial-related platform, and participatory network platform. The platform is divided into employment, funding, marketing, and e-commerce areas from the business persons' perspective. A representative area is LinkedIn. Users are instructed to write their career (work experience) and interest in their profile, and headhunters or employment personnel use the profiles. Funding is a platform used to receive investments based on various ideas or business plans, and crowdfunding is a typical funding platform. Marketing uses a platform for marketing purposes, including sales promotion, while portals or SNSs are the typical marketing platforms. E-commerce is a platform related to the transaction of goods or services. Not only Google Play or iTunes operating App markets, but various payment platforms are included in the e-commerce platform (Parket et al., 2016; Hagiu and Wright, 2015; Rogers, 2016).

A platform enables creating new values and connecting people, organizations, and resources in the interacting ecosystem to exchange these values. Therefore, the fundamental constitution analysis of platforms can be explained with opening, sharing, cooperation, and win-win partnership. If numerous people in diverse industrial groups pursue only their profits, the platform's role cannot be played. A platform system operator should maintain specific fees and its advertising income, whereas providers need to open preferred products and software information and prices, and cooperate in the delivery of orders and claim processes. Consumers should buy necessary products and software through set processes as a platform can grow when each role is based on opening, sharing, cooperation, and partnership.

Consequently, the need for the establishment of companies' platform leadership and capabilities is emphasized. Platform leadership signifies corporate capabilities, promoting innovation centered on specific platform technologies at an extensive industry level (Cusumano \& Gawer, 2002). Platform leadership can create business dynamism features such as internalities of a network, positive feedback effects, and bandwagon effects. Platform leadership has a merit that may bring about the virtuous circle of business and item production depending on motive and value awarded from complementary products or complementary producers (Lee et al., 2010). The determinant of platform leadership is the complementor, internal organization, and external relationship with platform technology. Cusumano and Gawer (2002) presented differentiated product technology to lead a system, firms' clear scope, win-win partnership, and relationship with external complementors. Leong et al. (2019) emphasized differentiated product technology, firms' clear scope, relationship with external complementors, and internal organization to implement responsibility policies.

Based on the platform's principle, firms should become solution providers by establishing platform leadership to organically combine ecosystem members, compose corporate ecosystem, use external ideas and R\&D resources, and implement open innovation. Also, platform strategy alongside platform leadership should be established. 
A platform strategy refers to a strategy creating network effects and building a new corporate ecosystem by gathering the participants of mutually different groups (Hirano \& Hagiu, 2011). A platform strategy in corporate business management strategy is a critical tactic for a firm's survival, and it was used for cost savings and product composition diversity before. Recently, however, a term of a platform strategy has been utilized in various areas within the value chain, including R\&D, production, marketing/sales, and after-sales service, centering on the ICT industry group as the ICT sharply develops due to the dissemination of the Internet and mobile technology (Choi, 2016).

To make the platform strategy feasible, the following conditions should be addressed: First, consumers from two or more types of classes should exist. Second, profits should be created by connecting different consumer classes. Third, consumers should obtain more benefits from the platform (Evans, 2003). A platform should be helpful for the management risks of the participating groups, and the characteristics in each group's specialized field need to be developed so that more participating groups can find values functionally (Hagel et al., 2008). Gawer and Cusumano (2007) put forward the commonly revealed factors among companies adopting the platform strategy. Some of them found the strategy a solution to problems and the connection easy to build up. Ben \& Lenfle (2010) presented balancing commonality, differentiation, and modularity as a favorable platform. Lee et al. (2010) leaned towards innovation ability, complementarities, efficiency, network effects, and connectivity.

Because a firm's vision and strategy are designed and implemented together, SMEs' platform leadership needs to be considered along with platform strategy. Consequently, SMEs' platform leadership will positively affect the platform strategy and play a vital role in successfully leading the strategy. This study designed the following hypothesis that SMEs' platform leadership positively affects the platform strategy.

$<$ Hypothesis 1> SMEs' platform leadership will have a positive effect on the platform strategy.

\subsection{SMEs' Digital Business Consolidation}

Amid the rapidly changing business environment, business digitalization is stressed through digital transformation. SMEs are required to establish strategic competitiveness for digital business capabilities and digital transformation. Rochet \& Tirole (2003) mentioned the importance of an intelligent factory, a business in which perfect communication is possible among stakeholders, smart products, and smart customers to whom ideas and orders are reflected. Lim (2013) emphasized the seven following characteristics as the necessary factors to be transformed as proper digital firms in the Fourth Industrial Revolution era: digitalization affecting corporate performance, digital integration enabling customers to make customization and individualization, digital culture, data analysis, data analysis capabilities, globalization, and the importance of appropriate investment.

The success of digital transformation can focus on the optimization of the value chain that is automatically controlled and makes dynamic production possible (Mrugalska et al., 2017). As Torkkeli \& Tuominen (2002) mentioned, a knowledge management system should be built through these primary factors: IoT, based on big data, real time, and sharing and cooperation of information. Overall, company constitution change and investment should be based on cooperation in which information is shared between a customer and a firm's internal and external connection such as digital technology, data system, and connectivity.

For SMEs, a new business model and effective business strategies to achieve business goals beyond conventional business and management techniques are necessary. At this point, the platform leadership and strategy place themselves as the strategy that companies commonly adopt for firms' continuous growth. The reason is that they are acknowledged as 
access consolidating a company's important innovation in various industrial groups by creating platform network effects and building new corporate ecosystems (Hirona \& Hagiu, 2011).

The key to digital transition rests on creating innovation through the strategic utilization of digital technology. Established companies also make a new productivity leap using digital technology. The well-known leading companies such as Google, Apple, Facebook, and Amazon not only accelerate the digital transition but solidify their status as a catalyst of the digital transition of different companies and industries. The leading companies' core competitiveness rests on platform capabilities, which are the combination of digital technologies. The platform does not mean supporting the digitalization level that simply changes work processes from offline to online. Instead, the platform becomes the central axis of business that innovatively changes its strategic direction and business model. This study presents the following hypotheses that platform leadership and strategy will affect digital business consolidation.

$<$ Hypothesis 2> SMEs' platform leadership has a positive effect on digital business consolidation.

$<$ Hypothesis 3> SMEs' platform strategy has a positive effect on digital business consolidation.

\subsection{Platform Business and Business Continuity}

Nowadays, companies feel the growth limitation in their business structures concerning the conventional value chain. They strongly recognize the need to carry out innovations and cope with changes to flexibly and quickly respond to customer needs (Chesbrough \& Adrienne, 2006; Chang \& Oh, 2013; Lee et al. 2016). A conventional business takes on a linear value chain structure, creating values going through linear steps from product and service manufacture and sale to users. Meanwhile, complex value is created through complex relationships among producers, users, and platforms in the platform business (Van Alstyne et al., 2016). As the platform business is applied to various industries, new competition order is created beyond the existing linear business model, and platforms become an essential factor for all companies' strategies (Hirano \& Hagiu, 2011).

One of the most essential activities for companies is building strategies for continuous growth through securing internal and external resources and capabilities (Porter, 1985). Companies should maintain a competitive edge in the market with their capabilities and performances in the changing market environment (Wu, 2007). Significantly, if SEMs utilize internal resources effectively and prepare for cooperative activities with external companies, this can positively affect the SMEs' performance (Yun \& Seo, 2016). To adapt to the rapidly changing business ecosystem and cope with the future environment, platform management activities are needed above all (Shapiro \& Varian, 2013).

Drawing cooperation synergy with external platform providers and obtaining digital technology rest on companies' attitude toward risks. SMEs need to consider the stagnation of platform growth and platform policy change as the service provider organization's risk becomes extinct according to platforms' status (Lee et al., 2010). To enhance platform capabilities, companies need to encourage risk-taking and system shift, increasing collaboration with many platform-related people/entities. Also, bold investment in digital data and information analysis accessing the changing environment should be made.

As Hesse (2007) asserted, companies can expand products and services through platform strategy, enhance organizational survival rate by expanding customers and markets, and continuously grow the organization. As Lee (2016) explained, corporate business digitalization can be promoted through platform business. To achieve sustainable growth, 
SMEs should maximize knowledge and technology-related resources and consolidate the platform leadership and strategy to invite external organizations. Based on this, SMEs need to consolidate business digitalization for their future values and continuous growth and seek digital innovation strategy. This study designed the following hypotheses based on previous studies:

$<$ Hypothesis 4> SMEs' platform leadership has a positive effect on business continuity.

$<$ Hypothesis 5> SMEs' platform strategy has a positive effect on business continuity.

$<$ Hypothesis 6> SMEs' digital business consolidation has a positive effect on business continuity.

\section{RESEARCH METHOD}

\subsection{Research Model}

This study empirically analyzed the effects of SMEs' platform leadership and platform strategy on digital business consolidation and business continuity. Based on previous studies' research hypotheses, this study composed the conceptual model, as shown in Figure 1.

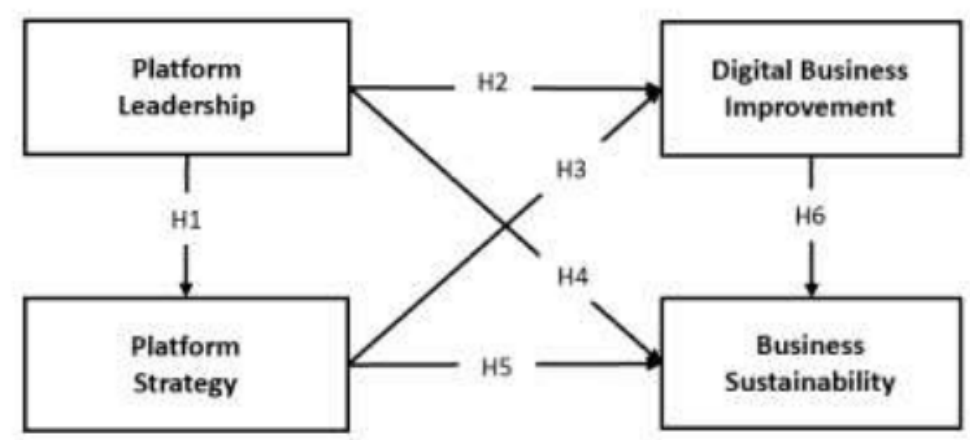

Figure 1 Research model

\subsection{Measurement Variable and Analytic Methods}

As shown in Table 1, this study designed each variable's organizational definition and measured questions based on previous studies. A total of 30 factors were significantly analyzed due to factor analysis, so they were used as final measurement factors.

The measurement items mentioned above were designed using the 5-point Likert measurement ( $1=$ not at all, $5=$ very so), and the questionnaire was patterned to it. For the descriptive statistical values and normalization analysis of demographic features and variables, SPSS 26.0 was used. To carry out a regression analysis and path analysis for the causal relationship analysis, AMOS 26.0 was used in terms of the structural equation model.

Table 1 Variable Definition

\begin{tabular}{|l|l|l|l|}
\hline \multicolumn{2}{|c|}{ Factors } & \multicolumn{1}{c|}{ Survey Items } & \multicolumn{1}{c|}{ References } \\
\hline & $\begin{array}{l}\text { Differentia } \\
\text { ted } \\
\text { Technolog } \\
\text { Platform } \\
\text { Leader- } \\
\text { ship }\end{array}$ & $\begin{array}{l}\text {-Have an excellent digital platform leading the market. } \\
\text {-Be equipped with outstanding technological } \\
\text { capabilities for a digital platform development and } \\
\text { utilization. } \\
\text {-Be active in new digital platform adoption. }\end{array}$ & $\begin{array}{l}\text { Cusumano \& } \\
\text { Gawer } \\
(2002) \\
\text { Lee et al. } \\
(2010)\end{array}$ \\
\cline { 2 - 3 } & $\begin{array}{l}\text { Clear } \\
\text { Business } \\
\text { Area }\end{array}$ & $\begin{array}{l}\text {-Use an excellent digital platform to achieve business } \\
\text { objectives. } \\
\text {-Use a digital platform to make a new business strategy } \\
\text { succeed. }\end{array}$ & $\begin{array}{l}\text { Leong et al. } \\
\text { (2019) }\end{array}$ \\
\hline
\end{tabular}




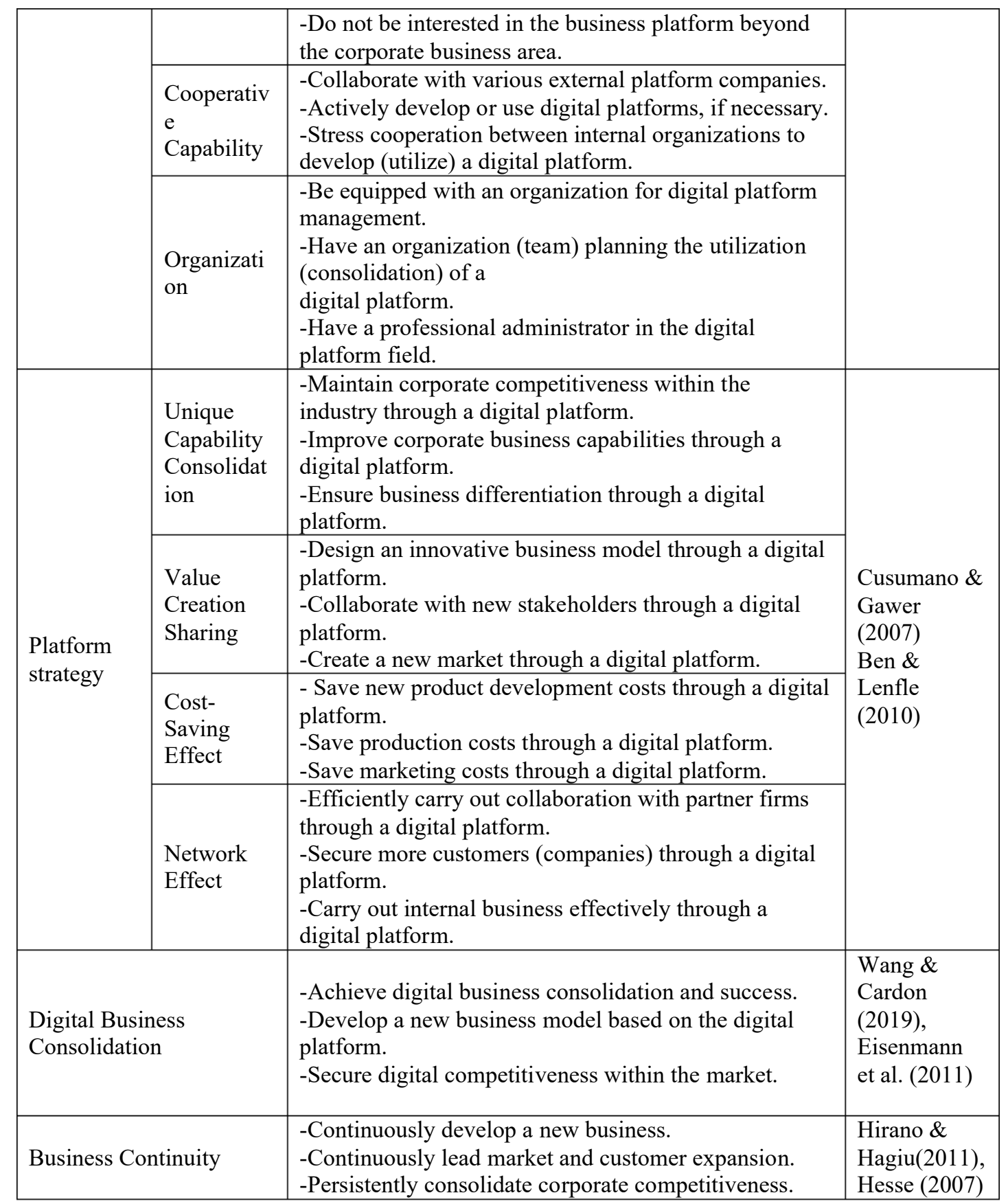

\subsection{Survey and Demographic Information}

This study targeted managers or professionals in higher positions in charge of management strategy and digital business work in SMEs, having 50 or more organization members in Korea and carrying out an online questionnaire survey for three months between July and September 2020. Four hundred five response copies were collected, and 376 copies were finally analyzed, except 29 response copies having insincere responses or defects.

Based on the response collection, $88.7 \%$ were males, and $11.3 \%$ were women; $0.5 \%$ were younger than $30,5.9 \%$ were in their $30 \mathrm{~s}, 24.5 \%$ were in their $40 \mathrm{~s}$, and $69.1 \%$ were at least in their 50s. Those 50 and above have a long work experience. Most of the respondents were highly educated people: $4 \%$ were high school graduates, $43.1 \%$ university graduates, $52.9 \%$ graduate school graduates or higher. As for work experience, $43 \%$ had less than 5 years, $1.6 \%$ 5-10 years, $8.2 \%$ 10-15 years, and $85.9 \%$ over 15 years. Concerning position, the 
employee/section chief composed $5.0 \%$, manager $7.5 \%$, director $10.5 \%$, and executive $77.9 \%$. Regarding the business type, $37 \%$ were in the manufacturing sector, $2.9 \%$ in the finance/insurance, $17.3 \%$ in the distribution, $34.6 \%$ service/R\&D, and $8.2 \%$ IT/ICT, with most being in the manufacturing and service industries. As to company size, $57.7 \%$ were less than 50 employees, the highest, followed by $14.1 \% 50-100,20.7 \% 100-300$, and $7.2 \%$ over 300 (see Table 2).

Table 2 Demographic Information of the Survey Participants

\begin{tabular}{|c|c|c|c|}
\hline \multicolumn{2}{|r|}{ Classification } & Frequency & Ratio \\
\hline \multirow{3}{*}{ Gender } & Male & 333 & 88.7 \\
\hline & Female & 43 & 11.3 \\
\hline & Total & 376 & 100 \\
\hline \multirow{5}{*}{ Age } & Younger than 30 & 2 & 0.5 \\
\hline & 30 - younger than 40 & 22 & 5.9 \\
\hline & 40 - younger than 50 & 92 & 24.5 \\
\hline & 50 or over & 260 & 69.1 \\
\hline & Total & 376 & 100 \\
\hline \multirow{4}{*}{ Education } & High school graduate & 15 & 4.0 \\
\hline & University graduate & 162 & 43.1 \\
\hline & Graduate school or higher & 199 & 52.9 \\
\hline & Total & 376 & 100 \\
\hline \multirow{5}{*}{ Work Experience } & Less than 5 years & 16 & 4.3 \\
\hline & 5 yrs - less than 10 yrs & 6 & 1.6 \\
\hline & 10 yrs - less than 15 yrs & 31 & 8.2 \\
\hline & 15 yrs or more & 323 & 85.9 \\
\hline & Total & 376 & 100 \\
\hline \multirow{5}{*}{ Position } & Employee/Section chief & 15 & 4.0 \\
\hline & Manager & 28 & 7.5 \\
\hline & Director & 40 & 10.6 \\
\hline & Executive & 293 & 77.9 \\
\hline & Total & 376 & 100 \\
\hline \multirow{6}{*}{ Business Type } & Manufacturing/Production & 139 & 37.0 \\
\hline & Finance and insurance & 11 & 2.9 \\
\hline & Distribution & 65 & 17.3 \\
\hline & Service R\&D & 130 & 34.6 \\
\hline & IT/ICT & 31 & 8.2 \\
\hline & Total & 376 & 100 \\
\hline \multirow{5}{*}{ Company Size } & Less than 50 & 237 & 57.7 \\
\hline & 50 - less than 100 & 54 & 14.1 \\
\hline & 100 - less than 300 & 78 & 20.7 \\
\hline & 300 or over & 27 & 7.2 \\
\hline & Total & 376 & 100 \\
\hline
\end{tabular}

\section{RESULTS}

\subsection{Analysis Results of Reliability and Validity}

The factor loading was $0.699-0.890$, and the $t$ values were all 10.0 or higher, so statistically significant results were revealed. The average variation value was $0.790-0.974$, and the Cronbach $\alpha$ value was $0.919-0.971$, so convergent validity was ensured. As a result of analyzing the fit of the measurement model, $\chi^{2}(\mathrm{df})$ was 487.890 and $\chi^{2}$ the degree of freedom was 6.983. Goodness of Fit Index (GFI) value was 0.931, Adjusted Goodness-of-Fit-Index (AGFI) was 0.912, Normal Fit Index (NFI) was 0.925, and Root Mean Square Error of 
Approximation (RMSEA) was 0.023. From there, the measurement model fit components were statistically significant.

Table 3 Results of Reliability and Convergent Validity Test

\begin{tabular}{|c|c|c|c|c|c|c|c|}
\hline Variable & $\begin{array}{c}\text { Measure } \\
\text { ment Item }\end{array}$ & $\begin{array}{c}\text { Standard } \\
\text { Loading Value }\end{array}$ & $\begin{array}{c}\text { Standard } \\
\text { Error }\end{array}$ & T-value & CR & AVE & $\begin{array}{c}\text { Cronbach } \\
\alpha\end{array}$ \\
\hline \multirow{4}{*}{$\begin{array}{l}\text { Platform } \\
\text { Leadership }\end{array}$} & PL1 & 0.898 & & & \multirow{4}{*}{0.911} & \multirow{4}{*}{0.72} & \multirow{4}{*}{0.934} \\
\hline & PL4 & 0.790 & 0.032 & $20.339 * * *$ & & & \\
\hline & PL3 & 0.834 & 0.039 & $22.612 * * *$ & & & \\
\hline & PL4 & 0.868 & 0.042 & $24.609 * * *$ & & & \\
\hline \multirow{4}{*}{$\begin{array}{l}\text { Platform } \\
\text { Strategy }\end{array}$} & PC1 & 0.931 & & & \multirow{4}{*}{0.952} & \multirow{4}{*}{0.832} & \multirow{4}{*}{0.971} \\
\hline & PC2 & 0.952 & 0.028 & $36.883^{* * *}$ & & & \\
\hline & PC3 & 0.855 & 0.035 & $26.204^{* * *}$ & & & \\
\hline & PC4 & 0.909 & 0.031 & $31.307 * * *$ & & & \\
\hline \multirow{3}{*}{$\begin{array}{l}\text { Digital } \\
\text { Business } \\
\text { Consolidati } \\
\text { on } \\
\end{array}$} & DB1 & 0.835 & & & \multirow{3}{*}{0.919} & \multirow{3}{*}{0.792} & \multirow{3}{*}{0.919} \\
\hline & DB2 & 0.910 & 0.049 & $23.108 * * *$ & & & \\
\hline & DB3 & 0.922 & 0.050 & $23.636^{* * *}$ & & & \\
\hline \multirow{3}{*}{$\begin{array}{l}\text { Business } \\
\text { Continuity }\end{array}$} & BS1 & 0.877 & & & \multirow{3}{*}{0.956} & \multirow{3}{*}{0.878} & \multirow{3}{*}{0.954} \\
\hline & $\mathrm{BS} 2$ & 0.974 & 0.035 & $31.596 * * *$ & & & \\
\hline & BS3 & 0.958 & 0.035 & $30.354 * * *$ & & & \\
\hline \multicolumn{8}{|c|}{$\begin{array}{l}\text { Measurement model fit: } \chi^{2}(\mathrm{df}) 487.890, \text { DF } 73, \chi^{2} / \text { degree of freedom } 6.983, \text { RMR } 0.032, \text { GFI } 0.925 \text {, } \\
\text { AGFI 0.849, NFI 0.927, TLI 0.922, CFI 0.937, RMSEA } 0.023 \\
* \mathrm{p}<0.05, * * \mathrm{p}<0.01, * * * \mathrm{p}<0.001\end{array}$} \\
\hline
\end{tabular}

According to the standard of Fornell \& Larcker (1985), discriminant validity between potential variables is said to be ensured if AVE's square root values calculated from each potential variable should be more significant than the correlation coefficient of another concept. This study examined the AVE values and correlation coefficients between potential variables to identify the discriminant validity. As shown in Table 4, the AVE square root value of each potential variable is more significant than the correlation coefficients of the variable concerned and other variables. The measuring tool ensured discriminant validity.

Table 4 Correlation Matrix and AVE

\begin{tabular}{|l|c|c|c|c|c|c|}
\hline \multicolumn{1}{|c|}{ Classification } & CR & AVE & PL & PS & DBC & BC \\
\hline $\begin{array}{l}\text { Platform Leadership } \\
\text { (PL) }\end{array}$ & 0.911 & 0.72 & 0.849 & & & \\
\hline $\begin{array}{l}\text { Platform Strategy } \\
\text { (PS) }\end{array}$ & 0.952 & 0.832 & 0.947 & 0.912 & & \\
\hline $\begin{array}{l}\text { Digital Business } \\
\text { Consolidation } \\
\text { (DBC) }\end{array}$ & 0.919 & 0.792 & 0.870 & 0.884 & 0.890 & 0.937 \\
\hline $\begin{array}{l}\text { Business Continuity } \\
\text { (BC) }\end{array}$ & 0.956 & 0.878 & 0.798 & 0.840 & 0.854 & \\
\hline
\end{tabular}

\subsection{Analysis Results of Structural Model}

As shown in Table 5 and Figure 2, this study drew the structural model's verified results. According to the fit standard, $\chi^{2}(\mathrm{df})$ was $465.842(\mathrm{p}=000), \chi^{2} /$ degree of freedom was 6.561 , GFI was 0.921, and AGFI was 0.841. RMSEA was 0.022, NFI was 0.931, and CFI was 0.942, so the explanation power was valid. 
As a result of examining the final structural model path coefficient for hypothesis verification, the platform leadership positively affected the platform strategy $(t=25.689$, $p<0.001)$. Platform strategy had positive effects on digital business consolidation $(\mathrm{t}=4.606$, $p<0.001)$ and business continuity $(\mathrm{t}=2.533, p<0.05)$. The platform strategy was especially analyzed to significantly affect digital consolidation activities than on business continuity. Digital business consolidation had a positive effect on business continuity $(\mathrm{t}=6.638, p<0.001)$, and so the hypotheses were adopted. However, platform leadership did not have direct effects on digital business consolidation and business continuity. The findings confirmed that platform leadership worked as a factor having effects on corporate digitalization and business continuity.

Table 5 Results of Hypothesis Test

\begin{tabular}{|c|c|c|c|c|c|}
\hline & Hypothesis & $\begin{array}{l}\text { Standardized } \\
\text { Factor } \\
\text { Loading } \\
\end{array}$ & $\begin{array}{c}\text { t-Value } \\
\text { (p) }\end{array}$ & $\begin{array}{l}\text { Status of } \\
\text { Acceptance }\end{array}$ & $\mathbf{R}^{2}$ \\
\hline H1 & $\begin{array}{l}\text { Platform Leadership -> } \\
\text { Platform Strategy }\end{array}$ & 0.953 & $25.689 * * *$ & supported & 0.908 \\
\hline $\mathrm{H} 2$ & $\begin{array}{l}\text { Platform Leadership -> } \\
\text { Digital Business } \\
\text { Consolidation }\end{array}$ & 0.118 & 0.710 & rejected & \multirow[t]{2}{*}{0.782} \\
\hline H3 & $\begin{array}{c}\text { Platform Strategy -> Digital } \\
\text { Business Consolidation }\end{array}$ & 0.77 & $4.606 * * *$ & supported & \\
\hline $\mathrm{H} 4$ & $\begin{array}{c}\text { Platform Leadership -> } \\
\text { Business Continuity }\end{array}$ & -0.053 & -0.334 & rejected & \multirow{3}{*}{$2^{0.76}$} \\
\hline H5 & $\begin{array}{c}\text { Platform Strategy -> Business } \\
\text { Continuity }\end{array}$ & 0.437 & $2.533^{*}$ & supported & \\
\hline H6 & $\begin{array}{c}\text { Digital Business } \\
\text { Consolidation } \rightarrow \text { Business } \\
\text { Continuity }\end{array}$ & 0.513 & $6.638 * * *$ & supported & \\
\hline \multicolumn{6}{|c|}{$\begin{array}{l}\text { 1) Structural model fit: } \chi^{2}(\mathrm{df}) 465.842, \mathrm{p} 0,00 \text {, DF } 71, \chi^{2} / \text { degree of freedom } 6.561 \text {, RMR } \\
0.031 \text {, GFI } 0.921 \text {, AGFI } 0.841 \text {, NFI 0.931, TLI 0.924, CFI 0.941, RMSEA } 0.022 \\
\text { 2) } * \mathrm{p}<0.05, * * \mathrm{p}<0.01, * * * \mathrm{p}<0.001\end{array}$} \\
\hline
\end{tabular}

\section{CONCLUSION}

This study shows that SMEs' platform leadership affects platform strategy and the platform strategy has a positive effect on business digitalization and continuity. As insisted in previous studies (Rochet \& Tirole , 2003; Evans \& Schmalensee, 2008; Lee et al., 2010), the result proves that the platform strategy is a vital management activity for firms' digital transformation. This study shows that SMEs' corporate business digitalization is an essential factor using platform business and platform strategy.

The implications of this study can be examined as follows: Previous studies were mainly on a strategy to enhance platform providers' network effects (Amit \& Zott, 2001; Van Alstyne $\&$ Parker, 2016). Strategic discussions on how platform providers continuously grow their platform business and expand new business models were mainly dealt with (Torkkeli \& Tuominen, 2002; Chesbrough \& Adrienne, 2006; Cho \& Part, 2015). However, producers' developmental discussions are also necessary as much as platform providers in the platform ecosystem are concerned. This study is meaningful because leadership and issues from the company aspects were presented to promote corporate development using platform ecosystems from the organizational behavioral level.

Second, since Cusumano \& Gawer (2002) defined platform leadership, the platform leadership theory has a limitation that it was not continuously connected to empirical 
research. However, leadership is essential for companies to take risks and innovatively promote platform business according to the feature that the company's external resources should be innovatively adopted and utilized in the platform business. For SMEs sticking to conventional business type and having limitations in bold investments in innovation, the platform business may need more powerful leadership. From this aspect, this study stressed the importance of platform leadership and proved positive effects on firms' digitalization based on platform strategy, which can be meaningful.

Third, this study has a meaning in that it empirically presented that SMEs' digital business consolidation can become a pivotal factor in corporate sustainability. As asserted from previous studies (Chang \& Oh, 2013; Hagiu \& Wright, 2015; Wang \& Cardon, 2019), SMEs should respond to quick IT knowledge-based economic trends amid today's environment. They may need a mid- and long-term development strategy based on digital transformation. However, as one company cannot lead digital technologies and strategies with just internal resources and capital, the platform strategy for external resources and the network was necessary for corporate future growth and continuity beyond business innovation.

This study has the following limitations: First, this study targeted Korean SMEs, and so the study results have a limitation that only Korean regional and economic features were reflected. Companies' platform business and digitalization levels vary according to national and economic characteristics. A further study needs to carry out studies targeting American, European, and Asian SMEs and draw differences and common country dynamics. Second, this study examined the relationships between factors on the digital consolidation and business continuity of platform leadership and strategy. However, the effect relationships of the platform leadership and strategy's sub-variables were not drawn, which can be a limitation. Discussions on what components should be considered to establish platform leadership and strategy can be meaningful in actual business. Therefore, further study is required to concretely examine the four components of platform leadership, namely differentiated technology, a clear scope of the firm, relationship with external complementors, and internal organizations to implement with responsibility, as well as the factors for platform strategy; that is, capability consolidation sharing, value creation sharing, cost-saving effect, and network effect.

\section{REFERENCES}

[1] Amit, R., \& Zott, C.(2001). Value creation in e-business. Strategic management journal, 22(67), 2001, pp. 493-520.

[2] Chang, J. H., Lee K. H. and Noh, K. S. A study on comparative analysis for competitiveness of success factors of the platform business. Journal of Digital Convergence, 14(3), 2016, pp. 243-250.

[3] Chang, K. Y. and Oh, J. S. A study on platform strategies of Korean first mobile instant messenger KakaoTalk. Asia-Pacific Journal of Business Venturing and Entrepreneurship, 8(4), 2013, pp.49-56.

[4] Chesbrough, H. and Adrienne, K. C. Beyond high tech: early adopters of open innovation in other industries. $R \& d$ Management, 36(3), 2006, pp. 229-236.

[5] Cho, H. J. and Park, C. H. The leadership competition of smart platforms in the ICT ecosystem: Comparative analysis of Samsung Electronics and SK Telecom in the accessory market. Asia-Pacific Journal of Business Venturing and Entrepreneurship, 10, 2015, pp. 187202. 
[6] Choi, H. D. The impact of regional and industry environments in shaping the organizational identity of the social enterprises. Asia-Pacific Journal of Business Venturing and Entrepreneurship, 11(4), 2016, pp. 117-126.

[7] Cusumano M. A. and Gawer, A. The elements of platform leadership. MIT Sloan Management Review, 43(3), 2002, pp. 51-58.

[8] Eisenmann, T., Parker, G. and Van Alstyne, M. Platform envelopment. Strategic Management Journal, 32(12), 2012, pp. 1270-1285.

[9] Evans, D. S. The antitrust economics of multi-sided platform Markets. Yale Journal on Regulation, 20(2), 2003, pp. 325-382.

[10] Evans, D. S and Schmalensee, R. Markets with two-sided platforms. Issues in Competition Law and policy, 28(1), 2008, pp. 667-693.

[11] Farrell, J. and Garth, S. Standardization, compatibility, and innovation, The RAND Journal of Economics, 16(1), 1985, pp. 70-83.

[12] GE Annual Report, What is Digital Transformation, 2018. 2. 23.

[13] Hagiu, A. and Wright, J. Multi-sided platforms. International Journal of Industrial Organization, 43, 2015, pp. 162-174.

[14] Hesse R. Two-sided platform markets and the application of the traditional antitrust analytical framework. Competition Policy International, 3(1), 2007, pp. 191-195.

[15] Hirano, A. C. and Hagiu, A. Platform Strategy, Seoul: The Soop, 2011.

[16] Lee, C. Y., Hwang, I. H. and Kim, J. S. The influential factors to growth intention and performance in earlystage technology-based start-up companies, Asia-Pacific journal of business and venturing, 11(2), 2016, pp. 49-62.

[17] Lee, K. N. Platform business concept and spread. Korea Information Society Development Institute, 28(14), 2016, pp. 30-35.

[18] Lee, S. M., Kim, T., Noh, Y. and Lee, B. Success factors of platform leadership in web 2.0 service business. Service Business, 4(2), 2010, pp. 89-103.

[19] Leong, C., Pan, S. L., Leidner, D. E. and Huang, J. S. Platform leadership: Managing boundaries for the network growth of digital platforms. Journal of the Association for Information Systems, 20(10), 2019, pp. 1-15.

[20] Lim, D. W. A Research trend of the platform strategy in a two-sided market. Korean Association of Industrial Business Administration, 28(1), 2013, pp. 109-139.

[21] Magretta, J. Why business models matter, Harvard Business School Publishing Corporation, May, 2002, pp. 86-92.

[22] Parket, G., Alstyne, M. W. V. and Choudary, S. P. Platform revolution, Baror International Inc., 2016.

[23] Porter, M. E.Technology and competitive advantage. Journal of business strategy, 5(3), 1985, pp. 60-78.

[24] Rochet, J. C. and Tirole, J. Platform competition in two-sided markets. Journal of the European Economic Association, 1(4), 2003, pp. 990-1029.

[25] Rogers, D. L. The digital transformation playbook, New York: Columbia University Press, 2016.

[26] Rysman, M. The economics of two-sided markets. Journal of Economic Perspectives, 23(3), 2009, pp. 125-143.

[27] Shapiro, C. and Varian, H. R. Information rules: a strategic guide to the network economy, Harvard Business Press, 2013. 
[28] Torkkeli, M. and Tuominen, M. The contribution of technology selection to core competencies. International Journal of Production Economics, 77(3), 2002, pp. 271-284.

[29] Van Alstyne, M. W., Parker, G. G. and Choudary, S. P. Pipelines, platforms, and the new rules of strategy. Harvard Business Review, 94(4), 2016, pp. 54-62.

[30] Wang C. and Cardon, P. W. The networked enterprise and legitimacy judgments: why digital platforms need leadership, Journal of Business Strategy, 40(6), 2019, pp. 33-39.

[31] Wu, L. Y. Entrepreneurial resources, dynamic capabilities and start-up performance of Taiwan's high-tech firms. Journal of Business research, 60(5), 2007, pp. 549-555.

[32] Yoon, B. S., \& Seo, Y. W. An empirical analysis of the effects of startup' activities of preparatory stage and early stage on performance, Asia-Pacific Journal of Business Venturing and Entrepreneurship, 11(4), 2016, pp. 1-15. 